\title{
Patient Perceptions of Epinephrine Auto-Injectors: Exploring Barriers to Use
}

\section{Abstract: 297 words}

Background: In recent years, government initiatives have proposed that patient selfcare should serve as a key resource in response to the anticipated increase in global demand for health care. However, if patients are to be empowered as self-carers, barriers to engagement must be identified and overcome. Anaphylaxis is an increasingly common life threatening allergic reaction. Patients at risk of anaphylaxis are prescribed epinephrine auto-injectors and play a crucial role in delivering their own care and management of this condition. One key recommendation is that patients routinely carry an epinephrine auto-injector with them, and deploy the device when needed. However, only a small proportion of patients that require epinephrine actually receive it.

Objective: To explore the reasons why patients who have been prescribed epinephrine auto-injectors fail to adhere to self-care and management recommendations.

Methods: In-depth interviews with 15 adults who have been prescribed epinephrine auto-injectors were carried out to explore the barriers that exist in the provision of effective self-care and management of anaphylaxis.

Results: Inconsistent health professional advice, perceived stigma of carrying a 'weapon-like' device, poor device design and limited patient training were identified as barriers to carriage or use. Patients were reluctant to carry devices in public because of perceived and observed stigma and suspicion. They were happy to ignore expiry dates and some participants were confident that the emergency services would provide them with the appropriate care they needed, and therefore did not carry the device in urban areas.

Conclusions and clinical implications: Improved training of patients, the public and health professionals around both the carriage and use of auto-injectors are areas for urgent attention if improved levels of self-care are to be attained. The design of epinephrine auto-injectors should also receive attention as patients often fail to carry them due to size and aesthetics. 
Key words: Adherence, allergy, anaphylaxis, empowerment, epinephrine, self-care, self-management, patient perspectives 


\section{INTRODUCTION}

With an anticipated rise in demand for health care resources (1-3), government initiatives see patient self-care and management as one of the few areas in which there still remains capacity for reducing costs whilst improving quality of service provision $(4,5)$. However, if the potential benefits in making a transition towards selfcare are to be fully realised, it is crucial that patients are able to deliver their self-care and management of this condition effectively (6). In-depth qualitative studies can assist in understanding the barriers that exist to patient engagement in the delivery of effective self-care and management (7), to provide insights into the self-care strategies that patients use for specific conditions/settings and suggest how these may be improved $(8,9)$.

Anaphylaxis is a life threatening allergic reaction which affects the respiratory and/or cardiovascular systems (10). Whilst anaphylaxis may be triggered by exposure to latex rubber, insect venom and medication, the most common cause is exposure to foods including peanuts, nuts, fish, milk and eggs (11). The incidence of anaphylaxis has risen dramatically in recent years as reflected by a 7 fold increase in anaphylaxis-related UK hospital admissions between 1990/1 and 2003/4(12). The treatment of anaphylaxis is a prompt intramuscular injection of epinephrine, typically administered by the patient themselves. It is therefore not surprising that prescriptions of epinephrine auto-injectors (EAls) have risen with 10,700 prescriptions being issued in England in 2001, to 21,100 in 2005 (13). Patients considered at risk of anaphylaxis are prescribed at least one EAl, which in accordance with self-care and management best practice for this condition, is to be carried by the patient at all times so that the device is readily available for rapid selftreatment when necessary (14). It is widely accepted that not having an EAI available at the scene of a severe anaphylaxis event puts the patient at significant risk of a fatal outcome (15).

A key component to ensuring anaphylaxis patients' needs are met is to ensure that allergy is thought of as a chronic condition (16). As with the majority of chronic conditions, key elements in the day-to-day management of anaphylaxis rely on the patient providing self-care to remain well and to be in a position to manage 
symptoms should they arise (17). Importantly there are characteristics of anaphylaxis that differ from that of most chronic conditions, which in turn impact on care strategies. As long as the patient avoids the responsible allergen, they remain entirely well. Some patients may only have had a severe reaction in early childhood which they cannot remember, and through successful allergen avoidance they may not have used their emergency treatments for some decades. However, they are at constant risk of a life-threatening reaction, should avoidance strategies fail, and continual vigilance and an ability to implement an emergency management plan at an unpredictable time is a daily requirement.

There is a lack of consensus in existing literature relating to the definition and scope of meaning of the term patient self-care and management (18). In this study, patient self-care and management is defined within the context of theory relating to management of chronic conditions; specifically within the emerging 'patientpractitioner partnership paradigm' (19). This paradigm suggests that patients managing chronic conditions should be recognised as experts on their own lives and should be their own primary care providers (20); the overriding role of the health professional within this is to act as a consultant and to support patients in managing their condition (21). Recognising and enabling patients to take the role of an expert provides the opportunity for patients to take responsibility, manage, problem solve, and make decisions about their own care. This is sometimes referred to as patient empowerment within this paradigm (22). In order to ensure patients are able to fulfil their expert self-caring role effectively, and to ensure a positive patient-practitioner care relationship is realised, two key enabling factors must be accommodated (19):

1) Provision of collaborative care: Recognition that patients have expertise of similar importance to that of health care professionals which are fully incorporated into the care delivery strategy.

2) Provision of self-management education: Patients are supported by health care professionals to develop problem solving skills, which enable them to make informed decisions about their self-care and management. 
Enabling patients to deliver effective self-care and management of chronic conditions has been shown to have a number of benefits including improvement of clinical outcomes (23) and in some cases reducing the overall cost of care (24).

Although EAls have been designed to be used as self-treatment devices by patients there is evidence to suggest that patients often do not engage in appropriate selfcare and management practices, such as the carriage and use of the device when necessary $(25,26)$. A study of fatal anaphylactic reactions revealed that only $10 \%$ of individuals actually had epinephrine to hand when it was required (27), and even when the device is to hand, it is often not used $(28,29)$.

Despite the serious consequences of not having such a device to hand, there is a lack of research that considers the experiences, attitudes and strategies patients use in the delivery of care and the management of this condition. To the best of our knowledge, little research has been carried out to specifically explore, from the adult patients' perspective, what patients motivations are for carriage or non-carriage of EAls and/or their deployment/non-deployment at appropriate times. The limited research that does exist includes a study of issues related to the use of EAls by adolescents (30) and exploring the psychosocial impact of anaphylaxis on young people (31), in which some initial insights are provided. For example, one participant in the latter study indicated that size of the device puts them off carrying it, and another participant suggested it is not easy to know how best to carry the device when taking it out and about. More generally, ensuring that medical devices are well designed and usable has been shown to have significant benefits including increased adherence for a wide range of users (32).

This study aims to investigate the experiences of adults who have been prescribed EAls, to better understand the barriers, from a patient perspective, to adhering to the self-care and management best practice recommendation of carrying the EAI at all times and its deployment when needed. Furthermore, taking into account the nature of these barriers, this study discusses whether improved levels of collaborative care and self-management education may go some way to help overcome the observed barriers to adherence. 


\section{METHODS}

\section{Participants}

A convenience sampling strategy was used to identify participants eligible to take part in this study. The inclusion criteria were adults between the age of 18 and 65 living in the South East of England, who reported to had been prescribed an EAI. A two-fold recruitment strategy was used. In the first instance, an email was sent out to all staff and students at Brunel University, inviting them to participate. Furthermore, an advertisement was placed in two freely circulated London newspapers, which also invited users to participate in our study. Severity of a participant's allergic reaction was graded using a classification previously used for peanut allergy (33). Eligible participants that responded to the university email and newspaper advert were then incrementally invited to take part in the interview sessions. Recruitment of participants for Interview ceased with data saturation, that is, when the researcher leading the analysis (AM) observed a clear pattern emerging in participant responses and subsequent responses appeared to become repetitious with no new themes being identified (34).

\section{Semi-structured interviews and data analysis}

In-depth semi-structured interviews and the completion of a brief questionnaire were carried out on a one-to-one basis with each participant. Interviews were conducted by the first author at various locations throughout London, according to the requirements of the participants. Consent was obtained to record interviews with a digital voice recorder.

The questionnaire collected basic demographics and information relating to each participant's allergy. In the subsequent interview, participants were asked to discuss more generally their experiences as a carrier and/or user of the EAI, their motivations for carrying or not carrying the device, the situations in which they carry or do not carry their EAls, the factors that affect whether or not they carry the device, and the design of the device, including which aspects the device design they would change if they could. Other topics discussed included friends and family's thoughts about their allergy and the EAI. Template analysis was used to analyse the interview data. This is a form of thematic analysis, which involves development of a coding template that represents a summary of the themes that are seen by the 
researcher(s) as being of importance within the data set (35). Analysis often begins with some a priori themes/codes that are of interest to the researcher, in this case, the interview data was approached with the broad aim of exploring factors that are related to and influence adherence with the EAI. Therefore, the approach taken in the analysis of this data is in line with what Madhill et al. (36) refer to as the 'contextual constructivist' position. In this case, it is accepted that there are many interpretations that may be made of a given phenomenon, which depends upon the focus of the researcher, and the context in which the research is carried out. Hence, the themes that emerge as a result of the analysis are partly a product of these factors.

As an initial step, all interview recordings were transcribed verbatim into text format by a trained transcriber. The textual dataset in its entirety was perused to conceptualise the overarching themes that existed at a high-level. The dataset was then perused for a second time, and sections of the text that corresponded with the focus of the research questions were taken note of. This process was carried out for the first three of the 15 interviews, after which, a number of over-arching themes representing the content within and across interviews was proposed as an initial coding template. Segments of text that corresponded with new themes as well as a priori themes were taken note of. The remainder of the dataset was then examined iteratively, enabling themes and sub-themes to be developed and modified as a result of carefully considering the contents of each transcript. This process was carried out by the first and second authors, who discussed inconsistencies where these arose, until a clear consensus of the main themes was reached (37). When no further refinement of the categorisation could be derived, a final template representing the themes and sub-themes identified within the full data set was produced, which was linked to the words of the respondents as they were presented in interview. For a detailed description of the thematic template analysis process, see King (35), and similarly for the thematic analysis process, see Joffe and Yardley (38) and Silverman (39). 


\section{Ethical considerations}

The study was reviewed and approved by the Brunel University Research Ethics Committee prior to any data collection. All participants taking part in the study were guaranteed confidentiality and anonymity. Signed consent forms were obtained from all participants prior to taking part in the semi-structured interviews. Participants were informed of their right to withdraw from the study at any time. This was done both in writing and verbally.

\section{RESULTS}

\section{Participants}

A total of fifteen participants (age 22-65 years mean 41 years; 10 female) were recruited, 12 via the London newspaper and three via Brunel University. Thirteen participants described themselves as 'White', one as 'Asian Pakistani', and one as 'Black Caribbean'. All participants had been prescribed the same brand of EAI (EpiPen). Eleven participants reported a previous reaction which warranted the administration of epinephrine, however, only seven of these 11 had used the EAI. Table 1 provides characteristics of the participants including what they are allergic to, whether they have used an EAI in the past, and the severity of their worst ever reaction (33).

Table 1: Characteristics of participants

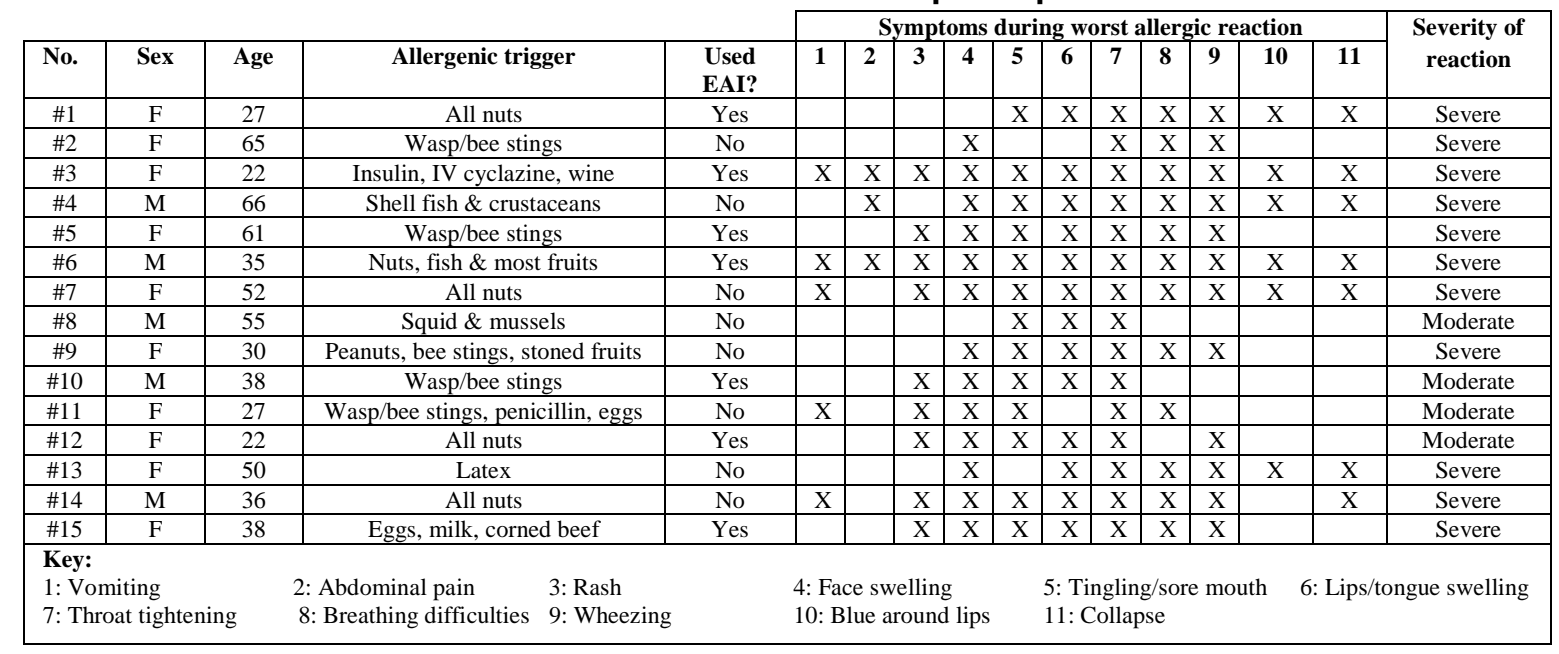




\section{Key themes}

Key themes identified in relation to EAls included: public acceptability of EAls; previous experiences; carrying the EAl; device design features. Quotes are labelled as participant number, and Severity = Severe, moderate or mild (33). Direct quotes from participants are included. Square brackets containing text [ ] are used to provide information that is required for clarification purposes.

\section{Public acceptability of EAls}

Participants identified a number of perceived and observed reactions to EAls by friends and the public. Participants felt that there was a lack of public awareness of what an EAI is or indeed what purpose such a device serves in the event of an anaphylactic reaction. As a result, there was concern as to how the device may be perceived, in terms of its function, but also what conclusions may be drawn, by members of the public, about the person who carries such a device. In some cases, it was felt that the device may be perceived as some sort of offensive weapon. Consequently some individuals expressed a reluctance to use the device in public.

\#15, Severe: I would definitely use it if I'm on my own, but if there's a group of us and that, I wouldn't. I wouldn't use it, no, I wouldn't do it - I would just...take myself away - know that it's coming on, and just go to the toilet or outside or something and just try and 'style it out' [laughing - and striking a pose]!

The perception of the EAI being as a weapon was further extended to the notion of the device posing a personal threat to the individual carrying it, which consequently caused them to question whether the benefits of carrying the device outweigh the potential risks. For example, if members of the public were to come to know that the patient was in possession of such a device, it may be used a weapon against them. Participant \#10 recalled a mugging incident, which caused him to worry for his own safety as a result of carrying the EAI.

\#10, Moderate: Em, there's been a couple of times - I don't live in the nicest of neighbourhoods. There's been a couple of times where I've been mugged, or almost mugged, and I've thought, "What would happen if they'd used that on me when I 
didn't need it?" So that's a concern as well, that it could be, in the wrong hands, it could be a...it could be an instrument that hinders your life rather than saves it.

Individuals also suggested that passing through security check-points often motivated them not to carry the device on their person at all. Attending football matches, night clubs, or passing through airport security typically were considered a potential cause of complications. Participant \#14 stated that he no longer carries his EAl with him to football games, because of the resistance he gets when being searched on entering the stadium.

\#14, Severe: Well, when I go to football, once a week... you get searched going into every away game, these days, and I didn't want to be sitting there causing a scene because I've got an EpiPen, you know, in case I'm going to sort of run on the pitch and stab one of the players with it. That's obviously what they think. You're not allowed knives, not allowed anything in, so why not this, you know?

It was also felt that carrying a drug such as epinephrine on ones person may invite others to draw unwarranted and unwanted conclusions that are potentially stigmatising, namely seeing the individual as a source of gaining access to a drug that could be used for recreational purposes. Such concerns motivated the individuals to either not carry the device or take care to conceal it from others. The following two quotes exemplify these points respectively.

\#15, Severe: ...embarrassment, mm, embarrassment, definitely...it makes me feel like I'm a bit labelled as, oh, there's something wrong with her - it's obvious there's something a little bit wrong with me..

\#12, Moderate: I mean, it is a drug... and people will do...do anything for a quick, you know, especially for a shot of adrenalin to... So em, you know, I don't like to declare it.

\section{Previous experiences}

Prior experiences also impacted on the extent to which the device was seen by participants as being of potential value in the treatment of an anaphylactic episode. 
Participant \#9 did unconcerned about not having an EAl with her at all times, largely as a result of having survived for 28 years without carrying such a device.
\#9, Severe: To be honest, I don't think about it. I've only had an EpiPen for about two years, so I've spent the first 28 years of my life without one. I guess people who are younger, who have always religiously carried one, they feel a little bit strange, but, for me, it's quite a recent thing...I don't think, oh god, I've forgotten it or missing it...Maybe, subconsciously, I think, well, I got through the last 28 years without one, I'll probably be okay.

Those with previous experience of using the device successfully reflected that they were unsure how effective the device would be prior to first using it and in particular whether the dose administered via the EAI would be sufficient to treat the onset of the anaphylactic reaction. In the comment below, Participant \#1 reflects on her first experience of using the device; particularly in the light of having to use two doses to gain the desired effect.
\#1, Severe: I wasn't sure if the EpiPen was going to work or not because I'd never used it before...I wasn't confident, and then, when I had to take the second one, I was even less confident, because I was afraid that it wasn't working [laughing], but then it did start to work quite quickly. And after, that first time, I've felt much more confident in them. I sort of feel pretty much totally confident that, if I need it, it will work.

Indeed for individuals that had never used the device, there seemed to be notable doubts over whether the EAI had any value in effectively treating an anaphylactic episode. For example, Participant \#14 reflects on his concern that the dose may be too low, and Participant \#4 expresses concern that the dose may be too high for treatment of a mild reaction.
\#14, Severe: I never carry it around, and I know I should do...but it's just, when I've been in hospital, the doctors have always said afterwards that it's taken quite a lot of adrenalin to sort of keep me alive...I always wonder if there's enough adrenalin in the actual EpiPen to actually keep me alive... but the fact is I don't trust it. I don't trust to see if it would actually work, because I've never actually used it....


\#4, Severe: What's a safe dosage of that for someone? You know, because you could be having a mild reaction, I suppose, and get nervous or panic, and do it, and if you had the wrong... if it was excessive, it could give you a heart attack. At my age, it might give you a heart attack. I don't know what it could do to you.

For the inexperienced user, there is confusion as to when the appropriate time is to deploy the device given the anxiety and uncertainty around deploying the device in error'.

\#11, Moderate: ...because I'm so unsure about how far it needs to get, like do I need to be going blue? You know, if my tongue starts swelling at all, should I use then? I've not got a clue...I mean I've not really had any training in it either. I got a little pamphlet, but that's not ideal, is it?

People who had previously used their EAl were more confident about using it again. Participant \#6, reported to have used the device in excess of 10 times in his lifetime.

\#6, Severe: So yes...there are things that can happen where you mistake it. However, the ambulance staff and the doctors afterwards - "You did the right thing. You thought you had an anaphylactic, and you've used that, like you would have in an asthma attack, you'd use your [Ventalin] - it makes no difference, you did the right thing." So I have no fear of using it at any time when I feel that I can't breathe and I've got the anxiety...I would use it, regardless, as a precaution.

\section{Carrying the EAI}

Carrying the device is of course a necessary but not sufficient prerequisite of use. Despite it being self-care best practice to carry the EAl at all times (40), some users conducted a risk assessment to decide when it was necessary to carry the EAI. In many cases participants were willing to delegate responsibility for providing rapid treatment of an anaphylactic reaction to the emergency services, particularly when it was perceived that such a service was in operation within the local area. Participant \#3 explains that she would be more likely to carry the device when in rural locations or environments where she had less knowledge of the emergency services, as opposed to when she was in more urban areas. 
\#3, Severe: I think...I think there's the reliance of, oh, I'm in the city, I'm going to be okay, there's so many hospitals, there's ambulances...you're covered kind of thing, compared to if you was in the middle of the mountains in Scotland or something like that.

This was echoed by a number of individuals, who on a day to day basis trusted that the emergency services would be available if required, and therefore felt safe not carrying the device. However, when abroad on holiday, it was seen as a necessity. Other factors that increased this necessity were the potential language barriers that may exist when ordering food in a foreign country. Participant \#9 reported that, apart from being on holiday, it is rare to have it on his person.

\#9, Severe: Very rarely. When I first got it, I was really good and very disciplined. More recently, I can't remember... I take it on holiday with me, but I'd probably say, in terms of percentages, I'd say maybe 5\% of the time or something like that.

\section{Device design features}

Participants drew attention to a number of factors related to the design of EAI devices that influenced whether they carried the device or predisposed its use in the event of an anaphylactic reaction. Participants commonly complained that the size of the device prevents them from carrying it, particularly as it is too big to comfortably fit the device into a trouser pocket. Participant \#1 reported needing to make special consideration to accommodate the device, typically in the form of a bag large enough to carry it.

\#1, Severe: The only thing I can think of is making it smaller, because that's the only thing that annoys me. Because it's quite long and sort of bulky, I mean, for what it is, it means I have to take a bigger bag than I otherwise would, or if I'm trying to sort of put it, you know, you can't put it in a pocket or somewhere if you're going to do something sporty.

In addition to the size of the device, the fact that there was no obvious means of 'clipping' it to one's person as a means of carriage was also noted as a factor that predisposed leaving it behind. Participant \#4 commented that if the EAI took the form 
of a standard ballpoint pen, carrying the device would be a simple task easily achievable on a day-to-day basis.

\#4, Severe: If you could design one that was like that (picking up a pen from the table), there's a future for you, mate! If that was the EpiPen, I could just put that...you know, go to the football, and just put it in my shirt, like this (clipping it in the Vof his shirt), but, you know, with these, you can't do that.

Many users felt that it would be beneficial to carry the device in the product cardboard packaging, as it was felt that there may be crucial information on the packet. Participant \#7 commented it is not feasible to carry the device in its package.

\#7, Severe: Well, you can't keep it in the box because it's huge and it's ridiculous, Toblerone-style affair. Then, you've got the plastic tube that it comes in, that you keep it in, which the lid bit of it always comes off. Then, you've got the length of it, which is too big, the whole thing is too big.

Participants frequently commented that EAl's have a surprisingly short use-by date. For a device that is ideally used infrequently, users suggested that these dates are unrealistically short, often resulting in the need to replace the device having never used it. In some cases, use-by dates were been reported to be as short as four weeks after the device was dispensed as indicated by Participant \#4.

\#4 Moderate: And when they hand one of those over to you...you need to check the sell-by date, because quite often, or sometimes, they might give you something which has only got four weeks, you know, eight weeks left... Whoever makes these, I think they're aggressive on the sell-by dates.

As a result of these short expiry dates, users sometimes took the decision to hold-on to devices that had clearly passed their expiry date. In a number of cases users reported to have been advised by health professionals to ignore the expiry dates, being told that the device will still have the required effect as long as the liquid in the device does not appear to be cloudy. Participant \#4 commented that he has never known any of his EAls to become discoloured or cloudy over 12 years and thus that they are safe to use. 
\#12Moderate: I believe the specialist said that they don't... they never really go out of date, but the time not to use it is when it's discoloured or when there's sort of condensation in the tube.

\#4, Severe: I'll bring one of my out-of-date ones and say, you know, "I'm putting it in the top of your liquor chest" or whatever, I've got one in there, in case we ever need it." so they know that there's a spare around...I've got one on my boat, you know, and in the glove-box of the car, just in case, you know, and I think they're probably still pretty good.

Participants reported that typically they were only able to obtain two EAls on prescription at any one time. Therefore, the assumption that the expiry date could be ignored, resulted in some participants accumulating several devices over a number of years. In order to overcome the awkwardness of carrying the device on one's person, these devices were distributed in a range of locations; in the hope that a device would be close at hand should the individual experience an anaphylactic reaction. Some of the locations participants reported to store the devices included friends or family members houses, in the glove box of the car, and in a desk drawer at work.

Participants suggested that EAls should be designed in the form of a less conspicuous everyday object, such as lipstick or deodorant. This seems to support the earlier theme Public acceptability of EAls, in that participants felt that the EAI was perceived as a weapon by members of the public. Participant \#15, when commenting on how the design of the device may be improved, commented as follows.

\#15, Severe: Like a little pouchy thing, you know, like a pretty, like you have for your phone, something like that, because it could be a lipstick, you know, a thin lipstick or one of them skinny deodorants or what have you, you know? But it's so revealing, through that glass case, that plastic case, it's so revealing. You know, it's yellow on yellow as well, and it's revealing, you know, like a weapon, sort of.

Indeed, some participants reported that they already disguise their EAI by carrying within an additional container. Some of the containers currently used include a cigar 
case, a children's pencil case and a glasses case. In the comment below, Participant \#12, comments on the use of a glasses case and its function.

\begin{abstract}
\#12Moderate: I just...I just feel it's... I don't really know. I think I've had it in a glasses case for so long I don't really know why anymore. It's... for me, it's just too obvious and too... If I'm rifling through my handbag and I have to get it out, people are... "What's that? Why do you have that?" and then you have to go off into this long story and... I don't, you know... If I just pop out a glasses case, people think it's a glasses case, and actually, I've got my contacts in today, but I do normally wear glasses.
\end{abstract}

\title{
DISCUSSION
}

With the increasingly central role the patient is expected to play in the delivery of their own care (5), there is a need to gain in-depth insights into the barriers that currently exist in delivering effective patient self-care and management for specific conditions/settings (7). In this study, 15 in-depth interviews were carried out with individuals that have been prescribed EAls for the self-care and management of anaphylaxis. Analysis of the interview data aimed to gain detailed insights into the barriers that exist to patients adhering to self-care best practice recommendations for this condition; the carriage of the device at all times and its deployment when necessary. The results revealed four high-level themes: Impact of experience; Previous experiences; Carrying the EAl; Device design features. Based on the findings of this study, it appears that patients see a number of barriers to carriage and use of EAls. Table 2 summarises the barriers to use and makes some recommendations as to how these may be overcome.

Some barriers to carriage and use may be overcome by improving the knowledge and training that is delivered to patients and those around them, including selfmanagement education which will enable patients to make informed decisions about their care $(19,23)$. Other barriers have implications for education of members of the wider community, for example, security staff. Importantly, there are design features of the EAls, that participants found challenging, particularly the size and short shelf life. If patients choose to leave their device at home because of its size, the 
Table 2: Barriers to EAl use and recommendations of how these barriers might be overcome.

\begin{tabular}{|l|c|c|c|}
\hline Public acceptability of EAIs & $\begin{array}{c}\text { Training/ } \\
\text { education } \\
\text { public }\end{array}$ & $\begin{array}{c}\text { Training/ } \\
\text { education } \\
\text { patients }\end{array}$ & $\begin{array}{c}\text { Device re- } \\
\text { design }\end{array}$ \\
\hline- Reluctance to use in public due to public perceptions & $\mathrm{X}$ & $\mathrm{X}$ & $\mathrm{X}$ \\
\hline- Perceived threat to carrier & $\mathrm{X}$ & $\mathrm{X}$ \\
\hline- Perceived as weapon by security staff and public & $\mathrm{X}$ & $\mathrm{X}$ & \\
\hline- Public perceptions of users and embarrassment of patients & & $\mathrm{X}$ \\
\hline Previous experiences & & $\mathrm{X}$ & \\
\hline- Previous experience of survival without device & & $\mathrm{X}$ & \\
\hline- Absence of positive life experience using device & $\mathrm{X}$ & \\
\hline- Not knowing when to deploy device & $\mathrm{X}$ & \\
\hline- Lack of knowledge regarding device efficacy and appropriateness of dose & & $\mathrm{X}$ & \\
\hline- Perceived fatal consequences of receiving a dose of epinephrine 'in error' & & & \\
\hline Carrying the EAI & & $\mathrm{X}$ & \\
\hline$-\quad$ Reliance on emergency services where possible & & \\
\hline Device design features & & & $\mathrm{X}$ \\
\hline- Size and shape & & & $\mathrm{X}$ \\
\hline- No means of clipping device to clothing & & \\
\hline- Short shelf life & $\mathrm{X}$ & $\mathrm{X}$ \\
\hline- Hostile looking device - too easily recognised & & & \\
\hline
\end{tabular}

prescription cost is wasted, and the patient is at increased risk in the event of anaphylaxis. The short shelf life also needs to be addressed. The current situation of short shelf life has cost implications, but is additionally putting patients at risk as they choose to attempt to overcome this by relying upon out of date devices. Some participants were under the misconception that the out of date device would be fine as long as the drug had not become discoloured. Although patients should be encouraged to check for discoloration, it must be emphasised that a clear solution is not a reliable indication of an adequate drug when the shelf life has been exceeded; use of time-expired devices has been associated with fatal cases of anaphylaxis (15, 41). Participants indicated that they are reluctant to reveal or use an EAI in public. Participants felt that the device may be perceived as an offensive weapon, a belief that was re-enforced when attempting to pass through security checkpoints. Efforts to educate the general public regarding these devices is needed, to improve awareness, familiarity and public acceptance of these devices, and to reduce the stigma perceived by allergic individuals. However, there also appears to be a need to better support the patient and provide them with improved levels of collaborative care, as is suggested to be a key enabling factor for patients to deliver effective selfcare (19). Better collaborative care is likely to improve levels of patient self-efficacy which in turn would increase patient self-confidence to reach the desired goal (20, 42), which in this case would be to carry and deploy the device, regardless of perceived stigma from members of the public. 
Improved knowledge and education of patients prescribed an EAI may also help to overcome a number of barriers to adherence. The participants in this study were recruited from non-medical sources. Some had been prescribed their EAI in primary care and others in specialist allergy clinics. The spectrum of training and advice that participants had received was therefore diverse, reflecting the reality of patients in the UK where allergy services are patchy $(43,44)$. Clearly, there appears to be a need, not only for self-management education (19), but also more traditional factual information specific to this condition. Many participants were unclear concerning basic information regarding their EAI and treatment of reactions. For example: Which symptoms justify the appropriate deployment of the device? How effective is the device in the treatment of anaphylaxis? Is the dose of epinephrine appropriate for any anaphylactic episode? Are the consequences fatal if a dose of epinephrine is received in the absence of anaphylaxis? In some cases, having lived a large proportion of their life without an EAI added to the questions of efficacy and indeed necessity of the device. Furthermore, some participants preferred to rely on emergency services for treatment of anaphylaxis, particularly in urban areas. This is a dangerous strategy, since it will delay the administration epinephrine and delayed treatment has been associated with fatal anaphylaxis (45). These barriers raise clear questions around the nature of training that patients have received, and whether they have been provided with appropriate self-management education in line with the patient-practitioner paradigm (19). Appropriate self-management education is a key factor that ensures that patients are able to make sensible decisions about their care, take appropriate action, and feel confident to alter actions as they experience changes in their individual circumstances $(20,21)$. Therefore it is likely that patients would benefit from receiving improved self-management education, which may lead to improved levels of adherence to self-care and management guidelines.

A number of participants indicated that a healthcare professional had advised them that it is safe to ignore the expiry date. This reflects the need for improved allergy training of professionals on very basic aspects of anaphylaxis self-care and management. Considerations relating to the device design may improve the number of patients who are prepared to carry their device. Adaptations may be made to the aesthetic features of the device, so that it appears to be less 'weapon like'. 
Participants suggested disguising the EAl, however, there are obvious risks and implications of disguising the device, not least the risk of the device not being recognised as an EAI by a member of the public, which may result in the patient not receiving treatment in the event of an anaphylactic episode. Furthermore, security personnel may be even less comfortable with admitting a person carrying a disguised 'weapon'. However, a design that appears less threatening would clearly be welcomed.

\section{Study limitations}

A potential limitation of this study was that participants were only recruited from the London area and indeed three of the participants were recruited from the same university although participants did span an age range from 22 - 65 years of age, and were from a range of ethnic origins. We recognise that the concepts of reliability and validity cannot be unproblematically applied to qualitative research data. However, in order to enable the reader to make a judgement as to whether the results of this study are transferable to other contexts we have sought to apply appropriate criteria to the conduct and reporting of this research: sensitivity in the interview procedure and protocol to the settings in which auto injectors might be used; commitment and rigour in both the data collection and analysis; transparency and coherence in the arguments articulated and in considering the impact of these findings for policy and practice (38).

\section{Conclusions}

In summary, we have investigated the barriers to effective self-care and management of anaphylaxis using EAls in a qualitative study of adults with allergy. The participants had received their allergy care in a variety of healthcare settings. Many revealed a poor understanding of how to self-manage a severe allergic reaction, despite having been prescribed treatment by a UK doctor. The study demonstrates an urgent need for improved education, both in terms of selfmanagement education and more traditional fact-based education relating to allergy. This education is required not only by patients and the general public, but importantly by health professionals who advise these patients on self-care and management strategies. There also appears to be scope to improve levels of collaborative care 
provision made available to patients, which may improve levels of patient selfconfidence and self-efficacy. Delayed or incorrect administration of epinephrine and failure to carry prescribed EAls is likely to cause fatalities. Education and training may improve the prognosis, but improvements in device design should also be addressed if patients are to be convinced to carry and use their EAls. 


\section{REFERENCES}

1. Shrestha LB. Population ageing in developing countries. Health Affairs 2000;19(3):204-212.

2. Darzi A, editor. High quality care for all: NHS next stage review final report. London: Department of Health; 2008.

3. Gilbert T, Powell J. Family, caring and ageing in the United Kingdom. Scandinavian Journal of Caring Science 2005;19(1):53-57.

4. Thompson AGH. The meaning of patient involvement and participation in health care consultations: A taxonomy. Social Science and Medicine 2006;67:1297-1310.

5. Dale B, Söderhamn U, Söderhamn O. Self-care ability among home-dwelling older people in rural areas in southern Norway. Scandinavian Journal of Caring Sciences 2011; In Press.

6. Sigurdardottir AK, Jonsdottir H. Empowerment in diabetes care: towards measuring empowerment. Scandinavian Journal of Caring Science 2008;22(2):284-291.

7. Money AG, Barnett J, Kuljis J. Public Claims About AEDs: An Online Consumer Opinion's Study. BMC Public Health 2011;11(332).

8. Sahlsten M, Larsson I, Sjöström B, Plos K. Nurse strategies for optimising patient participation in nursing care. Scandinavian Journal of Caring Sciences 2009;23(3):490-497.

9. Sacco-Peterson M, Borell L. Struggles for autonomy in self-care: the impact of the physical and socio-cultural environment in a long-term care setting. Scandinavian Journal of Caring Sciences 2004;18(4):376-386.

10. Muraro A, Roberts G, Clark A, Eigenmann PA, Halken S, Lack G, et al. The management of anaphylaxis in childhood: position paper of the European academy of allergology and clinical immunology. Allergy 2007;62(8):857-871.

11. Ewan PW. Anaphylaxis. British Medical Journal 1998;316(7142):1442-1445.

12. Gupta R, Sheikh A, Strachan DP, Anderson HR. Time trends in allergic disorders in the UK. Thorax 2007;62:91-96.

13. Skeikh A, Hippisley-Cox J, Newton J, Fenty J. Trends in national incidence, lifetime prevalence and adrenaline prescribing for anaphylaxis in England. Journal of the Royal Society of Medicine 2008;101:139-143.

14. Baral VR, Hourihane JO. Food allergy in Children. Postgraduate Medical Journal 2006;81:693701.

15. Pumphrey RSH. When should self-injectable epinephrine be prescribed for food allergy and when should it be used? Current Opinion in Allergy and Clinical Immunology 2008;8:254-260.

16. Walker S, Sheikhw A. Managing anaphylaxis: effective emergency and long-term care are necessary. Clinical \& Experimental Allergy 2003;33:1015-1018.

17. Choo K, Sheikh A. Action plans for the long-term management of anaphylaxis: systematic review of effectiveness. Clinical \& Experimental Allergy 2007;37(7):1090-1094.

18. Høy B, Wagner L, Hall EO. Self-care as a health resource of elders: an integrative review of the concept. Scandanavian Journal of Caring Science 2007;21:456-466.

19. Bodenheimer T, Lorig K, Holman H, Grumbach K. Patient self-management of chronic disease in primary care. Journal of the American Medical Association 2005;288(19):2469-2475.

20. Holman $\mathrm{H}$, Lorig K. Patients as partners in managing chronic disease. British Medical Journal 2000;320:526-527.

21. Funnell MM, Anderson RM. The problem with compliance in diabetes. Journal of the American Medical Association 2000;284:1709.

22. Arnold MS, Butler PM, R.M. A, Funnell MM, Feste C. Guidelines for facilitating a patient empowerment program. Diabetes Education 1995;21(4):308-312.

23. Vargas RB, Mangione CM, Asch S, Keesey J, Rosen M, Schonlau M, et al. Can a Chronic Care Model Collaborative Reduce Heart Disease Risk in Patients with Diabetes? Journal of General Internal Medicine 2007;22(2):215-222. 
24. Goetzel RZ OR, Villagra VG, Duffy J. Return on investment in disease management: a review. Health Care Financing Review 2005;26(4):1-19.

25. Cummings A, Knibb R, Erlewyn-Lajeunesse M, King R, Roberts G, Lucas J. Management of nut allergy influences quality of life and anxiety in children and their mothers Pediatric Allergy and Immunology, Volume 21, Number 4p1, 2010;21(4):586-594.

26. Macadam C, Barnett J, Roberts G, Stiefel G, King R, Erlewyn-Lajeunesse M, et al. What factors affect the carriage of epinephrine auto-injectors by teenagers? Clinical and Tranlational Allergy 2012;2(2):3.

27. Bock SA, Munoz-Furlong A, Sampson HA. Fatalities due to anaphylactic reactions to foods. Journal of Allergy and Clinical Immunology 2001;107(1):191-193.

28. Estelle F, Simons R. First-aid treatment of anaphylaxis to food: Focus on epinephrine. American Academy of Allergy, Asthma and Immunology 2004;113(5):837-844.

29. Simons KJ, Simons FER. Epinephrine and its Use in Anaphylaxis: Current Issues. Current Opinion in Allergy and Clinical Immunology 2010;10(4):354-361.

30. Gallagher M, Worth A, Cunningham-Burley S, Sheikh A. Epinephrine auto-injector use in adolescents at risk of anaphylaxis: a qualitative study in Scotland, UK. Clinical \& Experimental Allergy 2011;41:869-877.

31. Akeson N, Worth A, Sheikh A. The psychosocial impact of anaphylaxis on young people and their parents. Clinical and Experimental Allergy 2007;37:1213-1220.

32. Ward J, Clarkson J. Human Factors Engineering and the Design of Medical Devices. In: Carayon $\mathrm{P}$, editor. Handbook of human factors and ergonomics in health care and patient safety. Hillsdale, New Jersey, USA: L. Erlbaum Associates Inc.; 2006. p. 367-382.

33. O'B Hourihane J, Kilburn SA, Dean P, Warner JO. Clinical characteristics of peanut allergy. Clinical and Experiemntal Allergy 2006;27(6):634-639.

34. Guest G, Bunce A, Johnson L. How Many Interviews Are Enough? An Experiment with Data Saturation and Variability. Field Methods 2006;18(1):59-82.

35. King N. Using templates in the thematic analysis of text. In: Cassell C, Symon G, editors. Essential Guide to Qualitative Methods in Organizational Research. London, UK: Sage; 2004.

36. Madill A, Jordan A, Shirley C. Objectivity and reliability in qualitative analysis: Realist, contextualist and radical constructionist epistemologies. British Journal of Psychology 2000;91:1-20.

37. Braun V, Clarke V. Using thematic analysis in psychology. Qualitative Research in Psychology 2006;3(2):77-101.

38. Joffe H, Yardley L. Content and thematic analysis. In: Marks DF, Yardley L, editors. Research Methods for Clinical and Health Psychology. London, UK: Sage Publications; 2004. p. 56-66.

39. Silverman D. Doing Qualitative Research. London: Sage Publications; 2005.

40. Gosbee LL. Nuts! I Can't Figure Out How toUse My Life-Saving Epinephrine Auto-Injector! Joint Commission Journal on Quality and Safety 2004;30(4):220-223.

41. Pumphrey RS, Gowland MH. Further fatal allergic reactions to food in the United Kingdom, 1999-2006. Journal of Allergy and Cinical Immunology 2007;119(4):1018-1019.

42. Bandura A. Self-efficacy: The Exercise of Control. New York, USA: WH Freeman; 1997.

43. Holgate ST, Ewan PW. Allergy: the unmet need - a blueprint for better patient care. Royal College of Physicians 2003:1-93.

44. Finlay I. Allergy services: Still not meeting the unmet need. Royal College of Physicians and Royal College of Pathologists Working Party Report 2010:1-67.

45. Sampson HA, Mendelson L., Rosen J.P. Fatal and near-fatal anaphylactic reactions to food in children and adolescents. The New England Journal of Medicine 1992;327(6):380-384. 


\section{Legend for Tables}

Table 1: Characteristics of participants

Table 2: Barriers to EAI use and recommendations of how these barriers might be overcome 